\title{
7
}

\section{International Organizations and Education in the Islamic World}

\author{
David Krogmann
}

\section{Introduction ${ }^{1}$}

As education policy evolves into an increasingly internationalized field, the impact of international organizations (IOs) on national education policies is becoming more and more relevant. While research has been concerned with some of the more influential organizations in education policy, such as the Organisation for Economic Co-operation and Development (OECD), other IOs have largely flown under the radar. There are a number of education IOs of predominantly Muslim member

\footnotetext{
${ }^{1}$ This chapter is a product of the research conducted in the Collaborative Research Center "Global Dynamics of Social Policy" at the University of Bremen. The center is funded by the Deutsche Forschungsgemeinschaft (DFG, German Research Foundation)_-project number 374666841 SFB 1342.

D. Krogmann $(\bowtie)$

Institute for Intercultural and International Studies (InIIS) and Collaborative Research Centre 1342 "Global Dynamics of Social Policy”, University of Bremen, Bremen, Germany e-mail: krogmann@uni-bremen.de
} 
states that have not been reviewed systematically in almost 40 years of their existence. This chapter maps the existing education organizations in the Muslim world. The analysis presented here revolves around two main questions. First, which organizations consisting of predominantly Muslim member states are active in the field of international education policy, and how, if at all, do they cooperate? Second, which education leitmotifs and ideas do these organizations promote, what kind of discourse do they construct around education policy, and are aspects of it crucial for a particular 'cultural sphere' as defined in the introduction to this volume?

In answering these questions, this chapter also provides insights into existing discourses within a particular 'cultural sphere' proliferated by international organizations and how they are constructed as alternatives to or even contradictions against globally dominant discourses of education policy. It does so by focusing on the content of these discourses, rather than the mechanisms and power structures along which they are constructed. Using qualitative content analysis, this chapter explores the themes and ideas underlying the various activities of Muslim education IOs. For this purpose, the most relevant among Muslim education IOs are the Islamic World Education, Science and Culture Organization (ICESCO, formerly known as Islamic Educational, Scientific, and Cultural Organization (ISESCO)), ${ }^{2}$ a branch of the Organization of Islamic Cooperation, the Arab League Cultural, Educational, and Scientific Organization (ALECSO) and the Arab Bureau of Education for the Gulf States (ABEGS).

These three organizations are largely comprised of states with predominantly Muslim citizens and make frequent references to Islam in both their official statements and their publications. They also occasionally cooperate with each other, and there is a significant overlap in their membership. More precisely, all member states of the ABEGS are also members of the ALECSO, all of which are in turn members of ICESCO. In this chapter, I therefore refer to them as Muslim or Islamic education IOs, borrowing from Wayne Nelles' term "Islamic multilateral

\footnotetext{
${ }^{2}$ In 2020, the Islamic Educational, Scientific and Cultural Organization was renamed Islamic World Education Science and Culture Organization. As all documents reviewed in this chapter have been published before 2020, they will be referenced using ICESCO's former denomination ISESCO.
} 
institutions" (Nelles 2006). Special attention will be given to the ICESCO since it is the largest Muslim education IO. As such, it enjoys a unique status, not least because it explicitly promotes the religious dimension of education. The frequent references to religion, which informs both ICESCO's goals and the means it chooses to achieve them, separate the organization from its more universally oriented counterparts. Whereas organizations like the UN agencies are secular by nature, ICESCO is distinctly nonsecular.

Following a few remarks about the existing literature on Muslim international organizations in the next section, this chapter will first briefly introduce leitmotifs and ideas in education policy. It will then examine data generated from publications produced by the ICESCO, the ALECSO, and the ABEGS, presenting recurring themes found in these documents. The analysis will assess the proclaimed goals of the organizations for education policy, as well as their means of choice to achieve them, both of which are assumed to be informed by underlying ideas on how education should be conceptualized. After giving some space to the discussion of the results, the chapter concludes with a brief outlook on the challenges for further research in this field.

The analysis finds that Muslim education IOs participate in a distinct discourse that revolves around the synthesis of traditional values drawn from Islamic philosophy and the demands of a modern global labor market. Furthermore, it calls into question the effectiveness of said organizations in resolving the assumed conflict between traditional Muslim education and a "Westernized" world, as Muslim education IOs face shortages in budget and staff.

\section{Contextualizing Education Leitmotifs in Muslim IOs}

A large part of the motivation for this chapter stems from the fact that we know almost nothing about Muslim education IOs, despite them being around for more than four decades. Literature on these organizations is exceptionally limited, adding some weight to Wayne Nelles' claim that 
"the international community as a whole has not well analyzed, engaged with, or understood Islamic multilateral institutions" (Nelles 2006, 123).

Nevertheless, three basic points have been made by scholars in regard to the organizations examined here. Firstly, being one of the few scholars to have published on Islamic IOs, Nelles notes that most of them share a "profound concern" in regard to their cultural identity, namely, that Western culture, as well as globalization, puts serious pressure on many Islamic countries wanting to preserve their cultural and spiritual roots (Nelles 2006), something that many Westerners have "never come to terms with" (Nelles 2006, 122). Currie-Alder (2019) argues that strengthening the common cultural identity among Muslim countries has been one of the key motivations behind the foundation of various multilateral organizations in the Muslim world. Baghdady discusses the fundamental conflicts between the values proliferated by Western models of education and what he calls "Arab and Islamic cultures" (Baghdady 2019, 257), arguing that some Muslim-majority states have been resistant to accept foreign cultural norms and objectives in education. Secondly, connected to this conflict, spiritual development or self-refinement seems to be a much more important educational objective for many Muslim countries, especially in the Arab world, than for many Western countries, when compared for example with individual prosperity or economic growth (Findlow 2008). This is not to say that economic growth, skilled human capital, and other economic objectives of education policy are irrelevant for the organizations covered here. Rather, previous comparative work on national education policy in the Gulf region suggests strategical and situational "re-drawing of structures, priorities, collectivities and paradigms" as the main feature of education policy (Findlow and Hayes 2016, 125). Some nations, at least in the Gulf region, tend to use international input in education strategically to reach their economic goals (Hayes and Al'Abri 2019). Finally, Muslim education IOs do not enjoy the same level of trust as, say, United Nations Educational, Scientific, and Cultural Organization (UNESCO) or the OECD. For example, Kayaoglu finds that the Organization of Islamic Cooperation (OIC) and, by proxy, ICESCO, is often viewed as "inefficient, weak, and useless, and thus a disservice to Muslims” (Kayaoglu 2015, 3). 
These points, while scarce, set a few expectations for the analysis. It is especially interesting that the findings provided in this chapter fit well with the arguments made by Nelles and Findlow. Moreover, my findings are in line with the idea that discourses on education policy comprise aspects related to the reproduction of culture within the respective 'cultural sphere': It seems that, indeed, cultural identity and spiritual refinement rank a lot higher on the Muslim education IOs' agenda than in other regional organizations.

A large part of the following analysis is concerned with leitmotifs in education policy. Therefore, it is necessary to elaborate on what a leitmotif is, which types of leitmotifs we find in education policy, and why they matter. A leitmotif is, defined in the simplest way, a dominant recurring theme in a given medium. Leitmotifs are constituted by a set of different ideas about education policy. I rely on Goldstein's and Keohane's definition, according to which an idea is simply a "belief held by individuals" (Goldstein and Keohane 1993, 3). For my purpose, this definition will be expanded to include not only beliefs held by individuals but also those held by IOs. Leitmotifs and ideas inform and guide education policy. They provide the framework for more specific goals that the Muslim education IOs might propose. How IOs frame education when they participate in discourse on specific education policy tells us how they think about education in general, which in turn informs their aims. This is important because for most education IOs, education is not a goal in itself but a means to an end (Martens and Niemann 2013). For example, an IO might pursue better learning outcomes to increase people's ability to participate in society, or to enhance their competitiveness in the labor market. As outlined in the introduction to this volume (Chap. 1; Nagel et al. 2010), this chapter differentiates between economic utilitarianism as well as social cohesion on an individual and collective level as the four main categories or leitmotifs under which education ideas can be subsumed. For the analysis of ICESCO, and to a lesser extent, ABEGS and ALECSO, a certain distinction or uniqueness can be expected in their education ideas. This is because the primary connection among ICESCOs member states is religious orientation, implying that both the social and the economic purposes of education policy may be adapted or expanded to include cultural-religious ideas. 
Much of what is presented below depends on qualitative content analysis of documents published by the examined organizations. Qualitative content analysis is the process of deducing meaning from the analysis of documented conversation of any kind (Schreier 2014). Three main criteria have been applied when selecting the documents, namely, relevance, availability, and time of publication. For my purpose, the most relevant documents are those that have a strategic component, that is, that set a more general vision on what the organization's education policy aims to achieve. This is because generally these documents clearly state their perceived purpose of education, rendering the analysis straightforward. Examples for relevant documents include strategic plans for the future, handbooks on education policy, or the charters of the IOs. Unfortunately, availability of documents is a huge concern when dealing with smaller IOs like the three cases presented here. Especially in the cases of ABEGS and ALECSO, the number of documents publicly available in English is limited. Therefore, any document excluded from the analysis has an immediate trade-off resulting in a smaller (and possibly insufficient) database. This means that one cannot apply criteria for relevant documents too rigorously when dealing with these organizations. In total, 26 publications have been examined for this chapter. The documents have been coded along the dimensions laid out in the theoretical framework using the qualitative analysis software MAXQDA. Altogether, 550 data points provide the basis for the following analysis.

\section{Similar, Yet Unique: Three Muslim Education IOs}

The organizations covered in this chapter have a limited presence in the global public and academic discourse on education IOs. Thus, it seems adequate to preface the analysis with a general outline of the ICESCO, the ALECSO, and the ABEGS. I briefly introduce these three organizations and provide an overview on how the organizations are set up, what their goals are, and what they do to reach them. Note that the ICESCO and the ALECSO are not exclusively tasked with education policy. 
Therefore, their charters and statutes encompass several goals in other policy fields, which are irrelevant for my purpose and only included if they provide insights into the organizational leitmotifs.

\section{ICESCO: Education Policy for the Ummah}

The Islamic World Education, Science, and Culture Organization, formerly known as Islamic Educational, Scientific, and Cultural Organization, is perhaps the most relevant Muslim education IO. Established by the member states of the OIC in May 1981 and officially founded in 1982, its membership has expanded from 28 founding members at the constituent conference to 54 member states today. As an official branch of the OIC, only OIC members can join the organization. ICESCO is comprised of states from all over the world with varying sizes and capabilities as well as resources. The Union of International Associations (UIA) classifies the ICESCO as an "intercontinental membership organization" (UIA 2019a), which means that its "membership exceeds that of a particular continental region, covers at least 10 countries, and is equitably distributed over at least two continents" (UIA $2019 b)$. As such, ICESCO is a very diverse organization in terms of the regional origin of its members. Most of its member states are situated in Africa and the Middle East, but there are exceptions like the Republic of Indonesia (joined in 1986) or the Republic of Guyana (joined in 2014). Interestingly, a number of states in the ICESCO only have a minor share of Muslim citizens, such as the Republic of Togo (est. 14\% Muslim population ${ }^{3}$.

\section{Goals in Education Policy}

The ICESCO's 2017 strategy paper "Development of Education in the Islamic World" outlines its current objectives for education policy. These objectives are based on perceived challenges that the ICESCO members face in today's world. According to the organization, the "major

\footnotetext{
${ }^{3}$ CIA World Factbook (2010): Togo.
} 
shortcomings in the education system of the Islamic World" (ISESCO 2017 b 29) include high illiteracy rates of up to $70 \%$ in some member states, poverty and huge income inequality, as well as great imparity in education between genders. In addition to these general problems, the ICESCO also identifies a number of more specific problems with education policy in many of its member states, such as deficient educational curricula, poor teacher training, insufficient spending on education, and low enrolment rates in all stages of the educational system (ISESCO $2017 \mathrm{~b}, 30$ ). Based on its perception of these problems, the ICESCO proposes some major objectives for education policy, which correspond to earlier publications (ISESCO 2014, 2016a) and to the charter of the organization (ISESCO 2015a). The societal objectives of the ICESCO for education are to

contribute to the development of educational systems [...] to build peaceful, knowledge-based and prosperous societies (ISESCO 2017b, 7), and to ensure the transition of Muslims from being dependent and passive consumers to being active international role players, developers and producers of knowledge in such a way as to allow the Islamic world to regain its leading role in building human civilization. (ISESCO 2017b, 7)

These statements also illustrate the difference between an objective and a leitmotif, in that the first part of the sentence represents the objective (e.g. "contribute to the development of educational systems") and the second part describes the purpose behind the objective (e.g. "to build peaceful and prosperous societies").

Furthermore, there is also an economic component in the educational objectives of the ICESCO. Education is supposed to not only create a knowledge-based society, but also help alleviate poverty and enable economic development of the member states. The summary of the ICESCO's proclaimed educational objectives is worth quoting in almost its full length here, since it is quite encompassing:

The objective is to reshape the roles of education in achieving sustainable development and facing present and future developments and requirements, ... enabling Islamic countries to engage in knowledge societies and 
contribute to knowledge production, thereby marking its presence in the writing of humanity's cultural history in its new form. (ISESCO 2017b, 13)

Thus, the ICESCO's educational objectives have both a social and an economic dimension. On the one hand, the economic development of the member states is only possible if the labor forces of the respective countries are equipped with adequate skillsets to enable them to participate in a global labor market. On the other hand, education should also ensure that Muslims all over ICESCO's members are aware of their cultural roots and their responsibility for a cohesive and peaceful knowledgebased society. However, the distinction between goal and education ideas becomes blurry in statements that highlight the cultural roots and religious tradition and at the same time proclaim the Islamic world's ambition to regain a leading role in human civilization and to participate in the writing of humans' cultural history. Proclaiming a particular kind of individual whose religiously influenced culture thrives toward a leading role in human civilization is an example of the importance of cultural spheres in global educational discourses. The objectives reflect the general ideas of the organization within the founding charter, which has been amended a number of times since its inception in 1982. The next chapter deals with them in detail.

\section{Leitmotifs and Education Ideas of ICESCO}

The ICESCO, like most education IOs, treats education as a multipurpose endeavor. In this view, education is crucial for skill formation, self-fulfillment, collective wealth, and the proliferation of collective social rights and duties. At the same time, the ICESCO has a clear focus, meaning that some education ideas are more important than others. In general, the ICESCO recognizes that education is an important tool for economic development on both the individual and the collective level. On the other hand, education has a significant social, especially cultural and religious element. While the economic element is, at times, clearly visible in the analyzed documents, the cultural and religious focus is what makes the organization unique among education IOs with a global reach. 
The ICESCO believes that an education policy that is suitable for the international Muslim community (the "Ummah") in general and its member states specifically has to be mindful of and informed by Islam and Islamic values. The significance of Islam for the organization's policy is made clear from the very first sentence of its charter, which states that Islam is "a religion of peace and tolerance, represents a way of life and a spiritual, human, moral, cultural and civilizational force" (Charter of the ICESCO, Preamble). Thus, if ICESCO is to successfully achieve its educational objectives, they have to be rooted "within the framework of the civilizational reference of the Islamic world and in the light of the human Islamic values and ideals" (Charter of the ICESCO, Art 4 (a)). Looking up to Western education systems as the singular source of inspiration for reforms in the Islamic world is counterproductive, according to ICESCO, because they are "alien to its cultural and civilizational references and incompatible with its socioeconomic context" (ISESCO 2017b, 16).

This sentiment can be found in every document published by ICESCO. Frequent references to religion are made in all reviewed documents, for example:

ISESCO hopes that this book will be yet another tool needed in enhancing the level of education in the Muslim world, ... within the framework of Islamic values that spur the Ummah to achieve greater civilizational progress and advancement. (ISESCO 2002, 6)

This [document] has been developed in accordance with the specific needs of Muslim communities and in line with Islamic teachings which regard education and learning (pursuit of knowledge) as an obligation for each Muslim. (ISESCO 2016b, 7)

[ISESCO aims to] preserve and enhance our common Islamic heritage to increase the awareness of the Muslim Youth of the values of Islam. (ISESCO 2005, 2)

The relationship between Islam and ICESCOs education policy is twofold. First, as noted before, its education objectives have to be mindful of 
Islamic culture and heritage; otherwise they cannot be achieved within the Ummah, because Islam is not only a religion, but "represents a way of life" (see above). Second, Islam also informs the education leitmotifs of ICESCO, since it provides a sense of what the ideal society to be achieved via quality education looks like, as well as an own legal system with the Sharia. Of course, not all member states of ICESCO refer to Sharia law in their legal systems. ICESCO, however, frequently does (see, e.g. ISESCO 2009, 2). The prominent role of Islam results in a vision of education focusing on spiritual self-refinement, collective norms, and duties drawn from a common cultural and religious background shared by all ICESCO member states.

This vision is further illustrated by a certain sense of a larger-than-life "Islamic civilization". While the notion of Islamic civilization is already present in the Charter, it is more explicit in later publications. The 2009 Khartoum declaration states the "renewed commitment and strengthened resolve" of ICESCO to "preserve and enhance the common Islamic heritage to increase the awareness of the Muslim children and adolescents of the values of Islam, and instill into them a sense of pride in the achievements of the glorious Islamic civilization" (ISESCO 2009, 2). Other documents stress the need to "allow the Islamic world to regain its leading role in building human civilization and spreading good and peace among humankind" (ISESCO 2017b, 7) and to "consolidate the civilizational identity of the Muslim world" (ISESCO 2017b, 25).

Second to spiritual refinement and collective religious participation, there is the leitmotif of economic development through quality education. In particular, ICESCO identifies the "need to harness the potential of human resources in Islamic countries and equip young people with basic skills for working life and professional integration [...] in order to improve living conditions and economic development" (ISESCO 2017b, 69). However, compared to other global education IOs such as the OECD and the World Bank (Niemann, this volume), human capital and economic growth seems to play a relatively small role in the discourse proliferated by ICESCO. The statement quoted above is in that way not representative of the general trend. The documents reviewed for this chapter rarely mention "human resources" or "human capital". In fact, the charter of the ICESCO does not refer to economic growth or the 
labor market at all, while the cultural purpose of the organization is very prominent. Economic growth is mostly presented as part of a larger bundle of educational objectives in ICESCO publications. Interestingly, ICESCO documents refer mostly to "socio-economic development" rather than just economic development (ISESCO 2002, 2009, 2017b).

This is not to say that ICESCO does not view economic development as an important benefit of quality education - it very much does. Rather, ICESCO attempts a delicate balancing act in "combining deep-rooted authenticity and enlightened modernity” (ISESCO 2017b, 12). ICESCO is aware that its member states desperately need improvements in education to reap the benefits of globalization and not be marginalized by it. However, its member states fear that they may lose their identities and cultural roots over the desperation for better education if they mindlessly assume Western education models, as many countries around the world have done (ISESCO 2017b, 16-18). Connected to said fears, the challenge of globalization is another prominent motif in ICESCO's publications. While most IOs recognize that globalization is not only a chance but also a challenge for many countries, ICESCO seems especially worried about its impact. ICESCO summarizes the challenge as follows:

Any new educational strategy in the Islamic world has to deal with globalization in such a manner as to take advantage of its positive aspects, ... while protecting the Muslim identity against the danger of melting into another culture in conflict with the religious, intellectual, social, moral and cultural components of the national Islamic identity. (ISESCO 2017b, 16)

Among the "positives of globalization" anticipated by ICESCO are intercultural dialogue and increased understanding between different countries and regions of the world, both of which are collective social undertakings. Mutual respect and understanding through intercultural dialogue enabled by globalization and modern communication technology will contribute to world peace and the advancement of human civilization. In fact, in a globalized world, "positive cross cultural fertilization and interaction is the only framework under which cultures can prosper" (ISESCO 2017b: 16). This notion is also reflected in a speech by Dr. Abdulaziz Othman Altwaijri, then Director General of ICESCO, held in 
2015, in which he noted that "infusing the contents of education curricula, science, culture and the media with then inherent tolerance of religious values is the right approach to building peace and promoting dialogue between the followers of religions, cultures and civilizations" (ISESCO 2015b, 13).

In sum, ICESCO discourse focuses a lot on the social dimensions, at both the individual and the collective level, while recognizing that there is a need for economic development. However, economic development is second to spiritual self-refinement and only needed insofar as it enables people to lead a good life and alleviate them from poverty.

\section{Activities in Education}

Having established the education ideas present in the analyzed publications, one should expect that these ideas are also reflected in the activities of ICESCO. ICESCO engages in a number of activities that are somewhat "typical" for large education IOs, such as organizing workshops, meetings, and conferences with stakeholders in the field, for example, the member states' ministers of education. Furthermore, ICESCO activities include publishing material on education policy, funding local projects, setting up educational centers, or participating in discourse via social media. Content-wise, these endeavors cover a wide range of both social and economic topics. This is especially evident from the workshops that ICESCO organizes, often in cooperation with other IOs or nongovernmental organizations (NGOs). For example, in 2018, ICESCO organized workshops on "professional methods to counter Islamophobia", on "recommendations for the development of a curriculum promoting the values of peace, harmony and tolerance", on "The Role of Crafts in Developing Community-based Economics in the Member States [sic]" and on "Integrating University and Private Sector Development [sic]", among others (OIC 2018). Further workshops include topics as diverse as environmental impact assessment, the protection of landmarks in Jerusalem, or financial support for women entrepreneurs in Chad. Most of these topics clearly reflect the leitmotifs covered above. Additionally, several workshops and training sessions demonstrate ICESCOs strong 
cultural focus. For example, ICESCO organizes training sessions in "traditional embroidery with gold and silk for women (Tahrira and Qasab)" (OIC 2016, 16) or "New Cultural Roles of Civil Society in Promoting and Disseminating Good Governance Culture".

Lastly, it is worth noting that ICESCO's budget also tends to provide greater financial means to social than to economic measures (ISESCO $2019,83)$, although a lot of measures in education policy, such as combating illiteracy, can be read as both an economic as well as a social project. While the budgetary items are sometimes ambiguous, there is a striking difference between the financial means attributed to skills and vocational education $(\$ 450.000)$ and those attributed to, for example, "traditional education" (\$1.000.000). One interesting finding on ICESCO's most recent budget report is the $\$ 450.000$ reserved for "the school of values and coexistence" (ISESCO 2019, 83). What ICESCO means with this illusive term is an education system "that aims to build a system of values in the minds of children and instill it in their daily behavior ... with respect for human rights, racial and cultural diversity and coexistence; drawing on the Islamic view that calls for taking care of the environment, healthy nutrition and human health and rationalize the use of natural resources endowed to people by Allah" (ISESCO 2019, 73). While this is not a very specific objective, it reinforces the importance that ICESCO assigns to what it views as the cultural roots of its member states in traditional Islamic values. In conclusion, this short analysis of ICESCO's activities shows that the elements presented above as ICESCO's leitmotifs are present in both the organization's day-to-day business as well as its budget.

\section{ALECSO: Education for the Arab World}

The Arab League Educational, Cultural, and Scientific Organization is a Tunis-based sub-institution of the League of Arab States. Founded in 1970, ALECSO is comprised of 22 member states today, most of which are situated in the Maghreb region and the Middle East. Similar to ICESCO, ALECSO's main task is the coordination of member state efforts in the fields of education, science, and culture. Many ALECSO 
member states are also member of ICESCO. We can, therefore, reasonably expect some similarity between the objectives and ideas of both institutions, given that they operate in the same fields.

\section{Education Goals}

ALECSO's perception of the challenges its member states are facing is largely similar to ICESCO. Key internal issues to be tackled are poverty, illiteracy, and inequality between genders. External challenges are posed by the danger of the deterioration of traditional values through "Western" cultural influence, the fierce competition in labor markets through globalization, as well as military threats. This last point seems weirdly out of place in an education document, as ALECSO refers to the challenge of "the foreign occupation of Palestine and Iraq, and the Golan Heights occupied by the Zionist entity, and conspiracies against some of the other Arab countries" (ALECSO 2008, 39).

According to ALECSO, its main overall objective in reaction to these various challenges is to promote "intellectual unity in the Arab World, through education, culture and sciences, and enhancing the level of culture in order to keep up with, and positively contribute to, universal civilization" (ALECSO 2017, 4). For higher education, this idea has recently been challenged significantly in national policies of the member states (Hayes and Al'Abri 2019). It remains to be seen if and how these challenges will find their way into the discourse produced by ALECSO.

For education policy specifically, ALECSO names an extensive list of objectives, among which a few stand out (ALECSO 2017, 4). These "key priorities" are to "guarantee quality education for all as a human right", to "provide learners with the tools for the acquisition, analysis, production and use of knowledge", to "strengthen capacities in education-related policy formulation, planning and management" and finally to "strengthen the Arab States' capacities in terms of data collection and use, and monitor best practices and experiences" (ALECSO 2017, 7). 


\section{Leitmotifs and Education Ideas of ALECSO}

ALECSO's education ideas are similar to those found in the published documents of ICESCO, where we find a "mixed bag" of supposed purposes of education, with an emphasis on societal advancement and both collective and individual spiritual refinement. On the one hand, ALECSO is aware of the economic problems of the Arab states. One of ALECSO's declared "essential leverage points" (ALECSO 2008, 39) is "enabling the learner to master the tools of knowledge ... and to acquire the skills and experiences necessary to increase his productivity and enhance his role as contributor to change and development" (ALECSO 2008, 40), because "human capital is the critical factor in moving forward to achieve prosperity" (ALECSO 2008, 6). This idea is also present almost word for word in other publications (ALECSO 2017, 7). "Education is the corner stone in the preparation, training and mobilization of the abilities of human capital" (ALECSO 2008, 6), and both individual and collective prosperity heavily depend on education as a driving force and an enabling system.

On the other hand, we find once again that ALECSO gives special attention to social purposes of education. ALECSO demands that "the philosophy of education be changed, so that building the student's personality becomes an essential axis in the educational process [...]; he can develop his/her spirit of citizenship and belonging, and be educated in human rights, tolerance, coexistence and dialogue" (ALECSO 2008, 9). For the individual, the key social purpose of education must be "developing the learner's abilities and meeting his various needs, particularly his physical and leisure needs, to increase his options for self-achievement" (ALECSO 2008, 40). This change in philosophy should be based on "the teachings of True Islam, as well as respect of other cultures and religions, in accordance with faith and conviction of the right to disagree" (ALECSO $2008,40)$. In terms of collective social purposes of education, ALECSO holds traditional values and norms as essential elements of the curricula when building a cohesive society. It argues that solidarity and individual responsibility constitute the basis for the social contract upon which the member states' societies are built. Arab societies can only prosper when 
their citizens are educated and know their rights and duties as well as the religious and cultural foundations upon which these are based (ALECSO 2008).

Lastly, there is a sense of regional identity that is supposed to be proliferated and strengthened by education policy, the concept of Pan-Arabism. Pan-Arabism implies a certain cultural uniformity shared by Arab people in the Middle East and the Maghreb region, which should also be reflected in the state system of these regions. Born over a century ago out of sentiments against British and French rule in the region, Pan-Arabism is anticolonial at its core and therefore emphasizes Arab autonomy (Reiser 1983). The specific expression of Pan-Arabism ranges from intergovernmental cooperation to calls for a united Arab nation. Indeed, PanArabism lies at the roots of the foundation of the Arab League itself. For ALECSO education policy, this idea means that education has an additional purpose- "the purpose being to strengthen the pan-Arab [sic!] sense of belonging and feeling" (ALECSO 2008, 40). Quality education must provide a sense of regional identity so that Arab citizens have a point of reference. This goes hand-in-hand with "increasing awareness of the major Arab issues" (ALECSO 2008, 40). It is interesting to see this idea spelled out explicitly because of the heavy implications that the term carries. One could interpret this as an added emphasis on the importance of Arab identity for ALECSO's education ideas.

\section{Activities in Education}

ALECSO, as an education IO, seems to follow a rather hands-off approach to pursuing its objectives. Compared to ICESCO, which actively intervenes in education policy with its own projects, such as workshops and training sessions that it hosts, ALECSO is focused on spreading awareness. ALECSO focuses on problems regarding education policy in member states, where it collects data, provides information to policymakers, and offers a platform of coordination. Indeed, ALECSO's declared code of conduct is to serve "as a house of expertise in the Arab World in all that relates to education, culture, science and communication" (ALECSO 2017, 10). The most important branch of ALECSO in 
this regard is the ALECSO Observatory, which was created as part of the Plan to Develop Education in the Arab World (2008). This institution is largely in charge of ALECSO's education policy research. It monitors the state of education in the Arab world, provides advice to policymakers, collects best practices, gathers and organizes data, and publishes a vast body of literature. The organization has, for example, published eight bulletins and reports on the general state of education, nine books and manuals relating to Arabic language education, a 24-part encyclopedia on great Arabic writers as well as roughly 30 books with synchronized learning material for Arab schools (ALECSO 2017). Furthermore, the organization publishes various bi-annual journals on education.

\section{ABEGS: Education Policy for the Gulf Region}

The Arab Bureau for Education in the Gulf States was set up in 1975 by seven member states from the gulf region, namely, Saudi Arabia, Yemen, Oman, Kuwait, the United Arab Emirates, Bahrain, and Qatar. All of these states are also members of the ALECSO and the ICESCO. ABEGS's raison d'être is similar in nature to ALECSO and, to a lesser extent, ICESCO. As per ABEGS's website, its task is to "promote cooperation and coordination in the fields of culture, education, science, information and documentation" (ABEGS 2019a), which is almost congruent with ALECSO's mission, albeit with a narrower regional focus.

\section{Education Goals}

ABEGS has published a number of comprehensive strategic goals along which it operates. The four key aims are, without any particular order, "developing the younger generations to promote citizenship values, developing educational policies and spreading the best practices, developing the Arabic language and the learning of it, as well as consolidating the roles of family and society in education" (ABEGS 2019a). These aims go hand-in-hand with ABEGS' mission, which the organization summarizes as "coordination of education development operations to reflect the 
Islamic nature of the region, to promote unity among its citizens and set educational plans based on modern scientific foundations" (ABEGS 2019b, 9).

\section{Leitmotifs and Education Ideas of ABEGS}

The above quote points to further similarities between ABEGS and the two other Muslim education IOs. On the one hand, the religious and cultural heritage of the region provides an important foundation without which a proper education system for the Gulf states cannot be realized. On the other hand, educational plans for the future should be based on "modern scientific foundations". This statement implies that ABEGS is well aware of the balancing act that it is tasked with-the synthesis of traditional values drawn from Islamic philosophy and the demands of economic development in a global labor market.

For the individual, quality education should entail that "young people can acquire behaviors which help them uphold their rights and duties as citizens, be in touch with their countries internal issues, while remaining positively open to up-to-date information in various fields, utilizing this information to help themselves and develop their countries" (ABEGS 2015,52 ). Once more, there is a focus on social rights and duties for individuals. Interestingly, a shared declaration of the United Nations Children's Fund (UNICEF), the United Nations High Commissioner for Refugees (UNHCR) and ABEGS, the Sharm El Sheik Statement from 2015, puts the focus on sustainable development and prosperity, where social cohesion comes as second priority:

We reaffirm that it [education] is a basis for the realization of other rights and essential for inclusive, equitable and sustainable development, as well as prosperity in the Arab states. ... We notably commit to the principle of education as a public good and a building block for prosperity, well-being, social cohesion and sustainable development. (UNESCO 2015, 1)

ABEGS's education ideas are thus a bit more balanced between social and economic concerns. 


\section{Activities in Education}

The ABEGS Strategy 2015-2020 lists 23 initiatives with 92 individual projects to be implemented until the year 2020. Among these are seminars, training sessions for stakeholders, the organization of regular coordination meetings, and a large number of publications. In fact, ABEGS claims to have published "hundreds of books and translations in various educational, scientific and cultural areas", which lead to its publications receiving "considerable interest and growing appreciation among people as valuable resource of educational Arab thought" (ABEGS 2019b, 29).

\section{Cooperation Between the Three Organizations}

Given the similarity of ABEGS, ICESCO, and ALECSO, both in terms of education ideas and member states, cooperation between the organizations is expected to a certain degree. Indeed, the organizations claim to cooperate on a lot of issues. In an attempt to institutionalize said cooperation, ICESCO has hosted a series of meetings between the three IOs. Most recently, they met in Rabat in 2017 at the 4th Forum of International Organizations. ICESCO Director General Dr. Altwaijri noted in his respective opening speech that "we must increase synergy and enhance cooperation between ICESCO, ALECSO and ABEGS" and that "the steadily growing scope of cooperation ..., and the rising trend of our accumulated expertise and accomplishments are proof that we are on the right track" (ISESCO 2017a, 2).

While these statements point to the existence of cooperation, it remains obscure which specific forms coordinated efforts by the three organizations assume. In other words, it is clear that ICESCO, ALECSO, and ABEGS do cooperate with each other, but less clear how they do so. Both of the most recent progress reports published by the OIC $(2016,2018)$, which thoroughly track ICESCO activities, do not mention joint action with ABEGS or ALECSO, and neither do ICESCO's tri-annual newsletters. Without further evidence, it seems that cooperation between the three organizations is more rudimentary than the statement above 
implies. To add to that observation, cooperation between but also within these organizations might be hindered by conflicts between the member states. Given the religious differences between some of the larger member states as well as their economic competition induced by geographical proximity, conflicts occur quite often. As Kayaoglu notes, "one can conclude that even fairly minor coordination issues can become extremely complicated when they involve differences in religious interpretation. ICESCO, like the OIC, is not strong enough to override the objection of a powerful member state in the name of the collective good" (Kayaoglu $2015,125)$.

\section{Conclusion}

The key findings from the analysis presented above can be summarized as follows. Firstly, ICESCO, ALECSO, and, to a lesser degree, ABEGS are quite clear in their emphasis on social purposes of education over economic ones, confirming expectations set by the literature (Findlow 2008). At the same time, all three organizations are aware of their member states' need for quality development policies, which education is a large part of. Secondly, there is a distinct cultural and/or religious element in the education ideas of the Islamic education IOs, which manifests itself in the references made to Islam and to a larger-than-life Islamic civilization. This means, thirdly, that Islamic education IOs engage in a balancing act quite similar to the Southeast Asian case presented elsewhere in this volume (Chap. 8). On the one hand, global labor markets require standardized education in order to be tapped into. On the other hand, "Westernized" education may be detrimental to the proliferation of traditional cultural-religious roots that the Islamic education IOs are committed to protect. This is challenging because global education policy is often secularized, while ICESCO is clearly not a secular organization. That is also what makes ICESCO a special case among global education IOs, in that most other global IOs are distinctly secular.

Indeed, the Islamic education IOs face a number of challenges that may seriously hinder their effectiveness in carrying out their designated missions. Differences in religious interpretations between Shia and Sunni 
countries respectively are an obvious example. As ICESCO, for example, commits itself to "publicizing the correct image of Islam", it remains unclear what "true Islam" constitutes. For ICESCO, this is further complicated by geopolitical tensions between large member states, such as Saudi-Arabia and Iran. Its relatively small budget only adds to these problems.

In sum, this chapter has undertaken a first mapping of Muslim international organizations in education policy. I have argued that Muslim education IOs engage in the production and reproduction of their own distinct ideas on how education should be conceived of, thereby, attempting a synthesis of traditional cultural and religious values drawn from Islamic philosophy and quality education for development purposes. Going forward, there remains a lot of potential for further research to expand upon these findings, especially since the analysis relied on a rather limited number of available documents for the ABEGS and the ALECSO. While it may be too early for a final verdict, the evidence hints at a connection between the globalization of education policy and the emergence of competing regional-cultural ideals of education. In a globalized world, some regional organizations may feel the need to protect their cultural roots against "Westernization" of education systems, possibly forming countermovements against global education IOs. While Samuel Huntington's Clash of Civilizations has been received very poorly in Western International Relations, and understandably so; a more subtle mechanism of a similar kind could be at play here. Some form of contradiction in their approaches toward education policy seems to exist between the different "civilizations" in the perception of the organizations reviewed here, as elusive and broad as this term may be. To acknowledge the fuzzy boundaries between different global cultures, Windzio and Martens (Chap. 1) introduce the concept of "cultural spheres" and Besche-Truthe et al. (Chap. 2) propose an appropriate methodology that accounts for this fuzziness in diffusion analyses. Is this a conflict between the regional and the global, or do these cultural spheres just indicate cultural difference, but coexistence, even though disagreement on the "writing of humanity's cultural history" will sometimes lead to tense relations between cultural spheres? ICESCO, for instance, regards "Westernized" education as a threat, rather than as a role model, but it is yet by no 
means clear what the implications are for the future global cultural development and the relations between the cultural spheres. Lastly, it remains to be seen whether there is any evidence for this development in other regions of the world before larger-scale conclusions can be drawn. Further research is needed to provide a more complete picture of the interactions between the global, regional, and local levels of education policy.

\section{References}

ABEGS. 2015. Strategy 2015-2020. Riyadh: ABEGS. org/about.

. 2019a. About Us. Accessed October 27, 2020. https://en.abegs. . 2019b. The Handbook. Riyadh: ABEGS.

ALECSO. 2008. A Plan for the Development of Education in the Arab Countries. Tunis: ALECSO. - 2017. ALECSO at a Glance. Tunis: ALECSO.

Baghdady, Ahmed. 2019. Governance and Education in Muslim-Majority States. In Global Governance and Muslim Organizations, ed. Leslie A. Pal and M. Evren Tok, 229-250. Cham: Palgrave Macmillan.

CIA World Factbook. 2010. Togo. Accessed October 9, 2020. https://www.cia. gov/library/publications/the-world-factbook/geos/to.html.

Currie-Alder, Bruce. 2019. Scaling Up Research Governance: From Exceptionalism to Fragmentation. In Global Governance and Muslim Organizations, ed. Leslie A. Pal and M. Evren Tok, 229-250. Cham: Palgrave Macmillan.

Findlow, Sally. 2008. Islam, Modernity, and Education in the Arab States. Intercultural Education 19 (4): 337-352.

Findlow, Sally, and Aneta Hayes. 2016. Transnational Academic Capitalism in the Arab Gulf: Balancing Global and Local, and Public and Private, Capitals. British Journal of Sociology of Education 37 (1): 110-128.

Goldstein, Judith, and Robert O. Keohane, eds. 1993. Ideas and Foreign Policy: Beliefs, Institutions, and Political Change. Cornell: Cornell University Press.

Hayes, Aneta, and Khalaf Marhoun Al'Abri. 2019. Regional Solidarity Undermined? Higher Education Developments in the Arabian Gulf, Economy and Time. Comparative Education 55 (2): 157-174.

ISESCO. 2002. Basic Needs for Women Education. Rabat: ISESCO. 2005. RabatDeclaration on Children in the Islamic World. Rabat: ISESCO. 
- 2009. Khartoum Declaration—Towards a Brighter Future for Our Children. Rabat: ISESCO.

- 2014. Rabat Declaration on Developing the Higher Education and Scientific Research System in the Muslim World. Rabat: ISESCO.

- 2015a. Charter of ISESCO. Accessed October 27, 2020. https://www. icesco.org/en/wp-content/uploads/sites/2/2020/01/charter-statutes.pdf.

- 2015b. Newsletter Issue 102. Accessed October 9, 2020. https://www. icesco.org/en/publications/.

- 2016a. Bamako Declaration on Higher Education. Bamako: ISESCO.

- 2016b. ISESCO's New Literacy Vision. Rabat: ISESCO.

- 2017a. Address by Dr Abdulaziz Othman Altwaijri at the 4th Forum of International Organizations. Rabat: ISESCO.

- 2017b. Strategy for the Development of Education in the Islamic World. Rabat: ISESCO.

2019. Three-YearAction Plan and Budgetfor 2019-2021. Rabat: ISESCO. Kayaoglu, Turan. 2015. The Organization of Islamic Cooperation. Politics, Problems and Potential. London: Routledge.

Martens, Kerstin, and Dennis Niemann. 2013. When Do Numbers Count? The Differential Impact of Ratings and Rankings on National Education Policy in Germany and the US. German Politics 22 (3): 314-332.

Nagel, Alexander-Kenneth, Kerstin Martens, and Michael Windzio. 2010. Introduction-Education Policy in Transformation. In Transformation of Education Policy, ed. Kerstin Martens, Alexander-Kenneth Nagel, Michael Windzio, and Ansgar Weymann, 3-27. Basingstoke: Palgrave Macmillan.

Nelles, Wayne. 2006. Education, Human Security, and the Terrorism Problematique: Reflections on UNESCO, ISESCO and Iran. Whitehead Journal of Diplomacy and International Relations 7 (2): 115-128.

Organization of Islamic Cooperation. 2016. Progress Report 2016-2017. Jeddah: OIC.

- 2018. Progress Report 2017-2018. Jeddah: OIC.

Reiser, Stewart. 1983. Pan-Arabism Revisited. Middle East Journal 37 (2): 218-233.

Schreier, Margrit. 2014. Qualitative Content Analysis. In The SAGE Handbook of Qualitative Data Analysis, ed. Uwe Flick, 170-183. Thousand Oaks: SAGE Publications.

UNESCO. 2015. Sharm El Sheikh Statement-Towards Quality Education and Lifelong Learning for All. Sharm El Sheikh: UNESCO. 
Union of International Associations. 2019a. Islamic Educational, Scientific and Cultural Organization (ISESCO). Accessed October 9, 2020. https://ybio. brillonline.com/s/or/en/1100035549.

2019b. Type 1 Codes. Accessed October 9, 2020. https://ybio.brillonline.com/ybguide/type1.

Open Access This chapter is licensed under the terms of the Creative Commons Attribution 4.0 International License (http://creativecommons.org/licenses/ by/4.0/), which permits use, sharing, adaptation, distribution and reproduction in any medium or format, as long as you give appropriate credit to the original author(s) and the source, provide a link to the Creative Commons licence and indicate if changes were made.

The images or other third party material in this chapter are included in the chapter's Creative Commons licence, unless indicated otherwise in a credit line to the material. If material is not included in the chapter's Creative Commons licence and your intended use is not permitted by statutory regulation or exceeds the permitted use, you will need to obtain permission directly from the copyright holder.

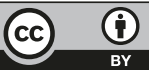

